\title{
New methodology for the walls design in buildings by numerical simulation of the thermal convection
}

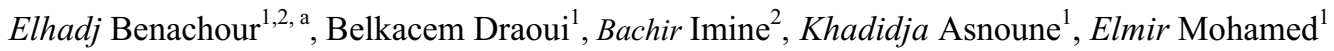 \\ ${ }^{1}$ Laboratory of Energy in Arid Regions, University of Tahri Mohamed - Bechar, P.O. P 417. 08000 , Road \\ Kenedza, Bechar, Algeria \\ ${ }^{2}$ Department of Mechanical Engineering, University of Sciences and Technology of Oran-Mohamed Boudiaf, \\ P.O.1505 El-Mnaouar, Oran, Algeria
}

\begin{abstract}
Buildings are complex systems composed of several elements, which are assembled to respond to a number of needs functional and symbolic according to set of legal and environmental requirements and potentially accommodate users with different levels of demand. Predicting the conception of the external wall is beneficial in the design of house and building structures.in this study, an analogy was used for the functions which are discretized by the finite difference method and integrated in the CFD code which is based on the finite volume method. The CFD software is used as a technique to modelling the behaviour of fluid and the thermal convection in the external wall of the house with different Rayleigh numbers $\left[10^{3} \leq \mathrm{Ra} \leq 10^{5}\right]$. In the second phase, we change the thickness of the wall several times and calculate the Nusselt number and exchange coefficient of heat transfer aims to find a cloud point respectively for the thicknesses e $=0, \mathrm{~L} / 40$, $\mathrm{L} / 20$ and $\mathrm{L} / 10$. After, we developed a relationship that helps us to know the exchange ratio for each thickness (e ) belongs to the interval [0, L / 10] by the Lagrange polynomial interpolation method for Rayleigh number equal $10^{4}$, and then we developed a FORTRAN program to control the nonlinear equation of order three. This method for predicting exchange coefficient of convection for to optimize the design of walls in buildings.
\end{abstract}

\section{Introduction}

The thermal behavior of buildings is a current problem Actually, In Algeria, The construction industry must start to take into account the changing needs of the population in its projects. It's not just homes that need to be adapted to ensure a safe and inclusive environment, but also the wider surroundings. Local shops and town centres have to be accessible and to accommodate the needs of people. This survey indicates that the biggest improvements could be made to the building sector, which must be properly adapted to ensure a safe environment for a workforce .The building sector today is known to be consuming $40 \%$ of the world energy $[1,2]$, and in turn, supports $23-40 \%$ of the world's greenhouse gas emission, particularly $\mathrm{CO} 2$ [3]. It has become common in recent years to gather data on human attitudes and behaviour in building energy research through interviews with building occupants and other relevant actors. Examples of this kind of research are found in the main journals which deal with technical aspects of energy in buildings, including Building and Environment [4-12], Building and Environment [13-15], Energy Storage [1620], Energy and Buildings [21-33]. In most situations, the mechanical cooling devices offer solutions that are neither environment friendly nor energy sustainable. The mechanical devices are non-functional and cannot offer thermal comfort without energy input. Hence utilization of advanced building materials and passive technologies in buildings may offer the solution for thermal comfort demands, substantially reduce the energy demand, impact on the environment and carbon footprint of building stock worldwide [34].Thermal comfort is dependent and influenced by a range of environmental factors viz. air temperature, radiant temperature, humidity, air movement, metabolic rate or human activity $[35,36]$. Also, numerous studies across the world have shown the impacts of hot working environments on the working population [37-43]. The choice of which material or combination of materials is used depends on a wide variety of factors. Some insulation materials have health risks, some so significant the materials are no longer allowed to be used but remain in use in some older buildings such as asbestos fibers and urea. Also, the cost can be high compared to the traditional insulation. The interior or external insulation does not often become the only possible solution in particular with the old buildings in the Sahara of Algeria. Hygrothermal parameters of the existing wall material should be reported and well known for designing powerful and durable walls in the time

\footnotetext{
a Corresponding author: benachour_elhadj@yahoo.fr
} 
study. First, in this paper, CFD software is used as a technique to modelling the behaviour of fluid and the thermal convection in the external wall of the house with different Rayleigh numbers $\left[10^{3} \leq \mathrm{Ra} \leq 10^{5}\right]$, In this context, an analogy was used for the functions which are discretized by the finite difference method and integrated in the CFD code which is based on the finite volume method. Secondly, The most important part in this work is to vary the thickness of the building material of the outer wall four times and calculate the Nusselt number and exchange coefficient of heat transfer aims to find a cloud point respectively for the thicknesses e $=0, \mathrm{~L} / 40$, $\mathrm{L} / 20$ and L / 10. After, we developed a relationship that helps us to know the exchange ratio for each thickness e belongs to the interval $[0, \mathrm{~L} / 10]$ by the Lagrange polynomial interpolation method, and then we developed a FORTRAN program to control the nonlinear equation of order three. This method for predicting exchange coefficient of convection to optimize the design of walls in buildings before starting the wall construction for Rayleigh number equal $10^{4}$.

\section{Geometric configuration}

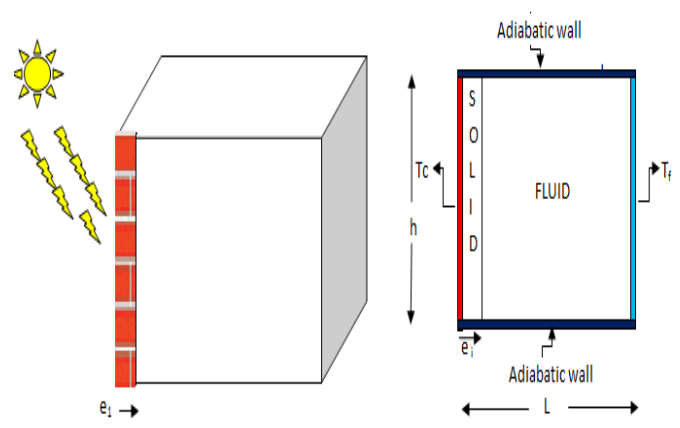

Fig. 1. Schematic of the studied configuration

To simplify the problem, assume that:

- The fluid is Newtonian and incompressible.

- The heat dissipation by viscous friction is neglected.

- The Boussinesq approximation is considered

\section{Objectives}

We can express our aim for this study in the following points:

- Prediction of the wall design through numerical evaluation of the convection in buildings by the Lagrange polynomial interpolation method.

- Modelling Study of the convection - conduction coupling.

- Study of the effect of the distribution of the heat inside buildings on the convection.

- Comparative study between the construction of buildings with different thicknesses and without insulation.
- Study the effect of the Rayleigh number on the convection in building.

\section{Mathematical model}

The fluid is assumed incompressible and obeys the Boussinesq approximation. In these cases, continuity in two dimensions and the equations governing the flow and energy is given by:

Continuity.

$$
\frac{\partial U}{\partial X}+\frac{\partial V}{\partial Y}=0
$$

\section{X-momentum.}

$$
\frac{\partial U}{\partial t}+U \frac{\partial U}{\partial X}+V \frac{\partial U}{\partial Y}=-\frac{1}{\rho} \frac{\partial P}{\partial X}+v \nabla^{2} U
$$

\section{Y-momentum.}

$$
\frac{\partial V}{\partial t}+U \frac{\partial V}{\partial X}+V \frac{\partial V}{\partial Y}=-\frac{1}{\rho} \frac{\partial P}{\partial X}+v \nabla^{2} V+g \beta \frac{\partial T}{\partial X}
$$

Energy.

$$
\frac{\partial T}{\partial t}+U \frac{\partial T}{\partial X}+V \frac{\partial T}{\partial Y}=\frac{\lambda}{\rho \mathcal{C}_{p}} \nabla^{2} T+\frac{1}{\rho \mathcal{C}_{p}} \varphi
$$

The derived equation of motion Eq. (2) over Y and the equation of motion Eq. (3) by contributing to $\mathrm{x}$, then, after subtracting the two equations obtained, we obtain the equations dimensionless variables in writing Helmotz in terms of vorticity and stream function formulation are as follows:

$$
\begin{aligned}
& \frac{\partial \omega}{\partial t}+U \frac{\partial \omega}{\partial X}+V \frac{\partial \omega}{\partial Y}=\operatorname{Pr} \nabla^{2} \omega+\operatorname{Ra} \operatorname{Pr} \frac{\partial T}{\partial X} \\
& \frac{\partial \theta}{\partial t}+U \frac{\partial T}{\partial X}+V \frac{\partial T}{\partial Y}=\frac{\partial^{2} T}{\partial X^{2}}+\frac{\partial^{2} T}{\partial Y^{2}}+\frac{\varphi}{\rho C p} \frac{L^{2}}{a \Delta T} \\
& \frac{\partial^{2} \psi}{\partial X^{2}}+\frac{\partial^{2} \psi}{\partial Y^{2}}=-\omega
\end{aligned}
$$

The stream function and vorticity are related to the velocity components by the following expressions:

$$
U=\frac{\partial \psi}{\partial Y}, V=-\frac{\partial \psi}{\partial X} \text { and } \omega=\frac{\partial V}{\partial X}-\frac{\partial U}{\partial Y}
$$

The dimensionless parameters in the equations above are defined as follows: 


$$
\left\{\begin{array}{l}
X=\frac{x}{L}, \quad Y=\frac{y}{L}, \quad U=\frac{u}{u_{i}} \\
V=\frac{v}{u_{i}}, P=\frac{P}{\rho u_{i}^{2}}, T^{*}=\frac{T-T_{i}}{T_{c}-T_{i}}, t^{*}=\frac{t}{L^{2} / a}
\end{array}\right.
$$

For solid (Concrete), we are interested only in the following heat equation:

$$
\frac{\partial T}{\partial t}=\frac{1}{a}\left(\frac{\partial^{2} T}{\partial X^{2}}+\frac{\partial^{2} T}{\partial Y^{2}}\right)
$$

\section{Procedure of simulation}

First, The numerical calculation was conducted using the GAMBIT and FLUENT software. The numerical procedure used in this work is that of finite volume. It involves the integration of differential equations of mathematical model on finite control volumes for the corresponding algebraic equations. In this context, an analogy was used for the functions which are discretized by the finite difference method and integrated in the CFD code which is based on the finite volume method. The SIMPLE algorithm [44] was chosen for the coupling speed pressure in the Navier-Stokes equations on a staggered grid. The convective terms in all equations are evaluated using the schema apwind first order. The discretization of the time term is made in a totally implicit scheme. The convergence of the solution is considered reached when the maximum relative change of all variables $(u, v, w, p, t)$ between two successive time is not less than 104 . With an aim of following well any variation of the fields thermal and hydrodynamic, we used a uniform grid of 14241 nodes and 14480 Elements in non-stationary mode. Secondly, we developed a FORTRAN program to control the nonlinear equation of order three. This method of interpolation was used for predicting exchange coefficient of convection to optimize the design of walls in buildings

\section{Validation of the Code of Calculation}

\subsection{Validation of the model}

The computer code was validated on a natural convection problem of stale air in a square cavity with vertical walls differentially heated and adiabatic horizontal walls. Our results were compared with those obtained by De Vahl Davis (1983) [45] .The latter dealt with the same problem by adopting the finite difference method with the vorticity-stream function formulation (see Table 1).

Table 1 Comparisons of the results of validation

\begin{tabular}{|c|c|c|c|}
\hline \multirow{2}{*}{$\begin{array}{c}\mathrm{Nu} \\
\text { (average } \\
\text { number) } \\
\text { (hot wall) }\end{array}$} & $\begin{array}{c}\text { De Vahl } \\
\text { Davis } \\
{[45]}\end{array}$ & $\begin{array}{c}\text { De Vahl } \\
\text { Davis } \\
{[45]:}\end{array}$ & $\begin{array}{c}\text { De Vahl } \\
\text { Davis } \\
{[45]:}\end{array}$ \\
\hline & 1.12 & 2.243 & 4.52 \\
\hline
\end{tabular}

\begin{tabular}{|c|c|c|c|}
\hline & $\mathrm{Ra}=10^{3}$ & $\mathrm{Ra}=10^{4}$ & $\mathrm{Ra}=10^{5}$ \\
\hline $\begin{array}{c}\mathrm{Nu} \\
\text { (average } \\
\text { number) }\end{array}$ & $\begin{array}{c}\text { present } \\
\text { study: } \\
\text { (hot wall) }\end{array}$ & $\begin{array}{c}\text { present } \\
\text { study : }\end{array}$ & $\begin{array}{c}\text { Present } \\
\text { study : }\end{array}$ \\
\hline
\end{tabular}

\section{Mathematical model for the lagrange polynomial interpolation method}

The Lagrange interpolating polynomial is the polynomial of degree $\leq(n-1)$ that passes through the $\mathrm{n}$ points $(\mathrm{x} 1, \mathrm{y} 1=\mathrm{f}(\mathrm{x} 1)),(\mathrm{x} 2, \mathrm{y} 2=\mathrm{f}(\mathrm{x} 2)), \ldots,(\mathrm{xn}$, $\mathrm{yn}=\mathrm{f}(\mathrm{xn}))$, the interpolation polynomial in the Lagrange form is a linear combination and is given by :

$$
P_{n}(x)=\sum_{i=0}^{n} y_{i} L_{i}(x)
$$

For Lagrange basis polynomials

$$
L_{i}(x)=\frac{\prod_{\substack{j=0 \\ j \neq i}}^{n}\left(x-x_{j}\right)}{\prod_{\substack{j=0 \\ j \neq i}}^{n}\left(x_{i}-x_{j}\right)}=\prod_{\substack{j=0 \\ j \neq i}}^{n} \frac{\left(x-x_{j}\right)}{\left(x_{i}-x_{j}\right)}
$$

Where

$$
\begin{cases}L\left(x_{j}\right)=0 & \text { if } i \neq j \\ L\left(x_{j}\right)=1 & \text { if } \quad i=j\end{cases}
$$

\subsection{The polynomial interpolation points}

We wish to find the polynomial interpolating the points

Table2 The sets of polynomial interpolation points.

\begin{tabular}{|c|c|c|c|c|}
\hline $\mathrm{B}=\mathrm{e} / \mathrm{L}$ & 0 & $1 / 40$ & $1 / 20$ & $1 / 10$ \\
\hline $\mathrm{Nu}_{\mathrm{a}}$ & 2.24 & 1.59 & 1.35 & 0.98 \\
\hline
\end{tabular}

Where, the points of $\mathrm{Nu}(\mathrm{e})$ are obtained by numerical simulation of the FLUENT software, for the Rayleigh number equal $10^{4}$.

\section{Results and discussion}

The boundary conditions have been established to simulate a geometric configuration used frequently in two-dimensional approximation. The structure of the flow, the temperature field and heat transfer through the hot wall are discussed in this section.In this study, to target the most important goal, we will show and studied the dynamic and thermal behavior of the fluid in the cavity.

\subsection{Isotherms}

The isotherms are shown in Figures [2]. The heat distribution in the cavity is in accordance with the fluid circulation revealed by isotherms and iso-currents. Indeed 
we find a heating fluid from the interface, if it causes the change of the heat distribution in the cavity (see figure) for different numbers of Rayleigh For a fixed value of the number of Prandtl equal 0.71 (air fluid). Gradually, as the Rayleigh number has increased, the isotherms become increasingly wavy and heat transfer increases, so the flow intensifies and natural convection is expanding and predominates (natural convection is predominant).

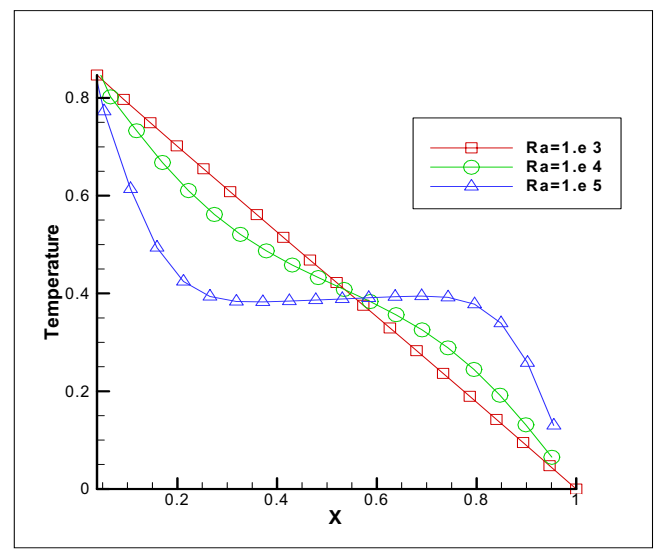

Fig. 2. The Isotherms for wall thickness $e=L / 20$, and for different Rayleigh Numbers, $\operatorname{Pr}=\mathbf{0 . 7 1}$.

\subsection{Lagrange polynomials}

The points of $\mathrm{Nu}$ (e) are obtained by numerical simulation of the FLUENT software, for the Rayleigh number equal $10^{4}$. (See table 3$)$

Table3 Nusselt number for different values of thickness. and for $R a=10^{4}$

\begin{tabular}{|c|c|c|c|}
\hline $\mathrm{Ra}$ & $\mathrm{i}$ & $\mathrm{Xi}=\mathrm{e}$ & $\begin{array}{c}\mathrm{Yi}=\mathrm{Nu}(\mathrm{e}) \\
\text { Average Nusselt } \\
\text { number }\end{array}$ \\
\hline $10^{4}$ & 0 & 0 & $\mathbf{2 . 2 4}$ \\
\hline $10^{4}$ & 1 & $\mathrm{e}=\mathrm{L} / 40$ & $\mathbf{1 . 5 9}$ \\
\hline $10^{4}$ & 2 & $\mathrm{e}=\mathrm{L} / 20$ & $\mathbf{1 . 3 5}$ \\
\hline $10^{4}$ & 3 & $\mathrm{e}=\mathrm{L} / 10$ & $\mathbf{0 . 9 8}$ \\
\hline
\end{tabular}

If $(0,2.24),(\mathrm{L} / 40,1.59),(\mathrm{L} / 20,1.35),(\mathrm{L} / 10,0.98)$, are given data points, then the cubic polynomial passing through these points can be expressed as,

$$
P_{3}(x)=y_{0} l_{0}+y_{1} l_{1}+y_{2} l_{2}+y_{3} l_{3}
$$

We would have the four basis polynomials

$$
\begin{aligned}
& l_{0}=\frac{\left(x-\frac{L}{40}\right)\left(x-\frac{L}{20}\right)\left(x-\frac{L}{10}\right)}{\left(0-\frac{L}{40}\right)\left(0-\frac{L}{20}\right)\left(0-\frac{L}{10}\right)} \\
& l_{1}=\frac{(x-0)\left(x-\frac{L}{20}\right)\left(x-\frac{L}{10}\right)}{\left(\frac{L}{40}-0\right)\left(\frac{L}{40}-\frac{L}{20}\right)\left(\frac{L}{40}-\frac{L}{10}\right)} \\
& l_{2}=\frac{(x-0)\left(x-\frac{L}{40}\right)\left(x-\frac{L}{10}\right)}{\left(\frac{L}{20}-0\right)\left(\frac{L}{20}-\frac{L}{40}\right)\left(\frac{L}{20}-\frac{L}{10}\right)}
\end{aligned}
$$

$$
l_{3}=\frac{(x-0)\left(x-\frac{L}{40}\right)\left(x-\frac{L}{20}\right)}{\left(\frac{L}{10}-0\right)\left(\frac{L}{10}-\frac{L}{40}\right)\left(\frac{L}{10}-\frac{L}{20}\right)}
$$

We can see that each term is of degree three, so the entire sum has degree at most three.

The polynomial $\mathrm{P}(\mathrm{x})$ given by the above formula is called Lagrange's interpolating polynomial and the functions Eq. (14, Eq). (15), Eq). (16), Eq.( 17) are called Lagrange's interpolating basis functions.

\subsection{Nusselt number correlations}

It should be noted that the numerical result given by the equation Eq.(20). Remarkably similar to the estimate of the average Nusselt number by the Lagrange interpolation method for each wall thickness between [0, L / 10] but only for $\mathrm{Ra}=10^{4}$.

$$
\begin{aligned}
& P_{3}(x)=y_{0} l_{0}+y_{1} l_{1}+y_{2} l_{2}+y_{3} l_{3} \\
& P_{3}(x)=2.24 l_{0}+1.59 l_{1}+1.35 l_{2}+0.98 l_{3} \\
& P_{3}(x)=-\frac{8960}{3 L^{3}} x^{3}+\frac{1656}{3 L^{2}} x^{2}-\frac{113.8}{3 L} x+2.24
\end{aligned}
$$

Therefore, we can write,

$$
\overline{N u}(e)=-\frac{2986.6}{L^{3}} e^{3}+\frac{552}{L^{2}} e^{2}-\frac{37.93}{L} e+2.24
$$

Where:

$$
\overline{N u} \text { : Average Nusselt number. }
$$

e : Wall thickness.

Also, we can write:

$$
\overline{N u}=-2986.6 B^{3}+552 B^{2}-37.93 B+2.24
$$

Where: $\mathrm{B}: \mathrm{e} / \mathrm{L}$

In heat transfer within a fluid, the Nusselt number $(\mathrm{Nu})$ is the ratio of convective to conductive heat transfer. The average value of the heat transfer coefficient is often needed in process engineering and design applications. In this context, the average Nusselt number is given by:

$$
\overline{N u}=\frac{\bar{h} H}{\lambda} \Rightarrow \bar{h}=\frac{\lambda \overline{N u}}{H}
$$

Where $\mathrm{h}$ is the convective heat transfer coefficient of the flow, $H$ is the characteristic length, $\lambda$ is the thermal conductivity of the fluid.

\subsection{Average Nusselt numbers}

The influence of the Rayleigh number and Wall thickness on the average Nusselt number is shown in Fig. 5 and fig 6. The Nusselt number decreases with increasing of the wall thickness. Therefore, the heat transfer also decreases because the inertia and the thermal resistance of the wall increases. The average value of the Nusselt number 
increases as the value of the Rayleigh number ( $\mathrm{Ra}$ ) increases. Broadly, advection becomes stronger and thus heat transfer increases. This trend is qualitatively consistent with that seen in the convection for important values of $\mathrm{Ra}$.

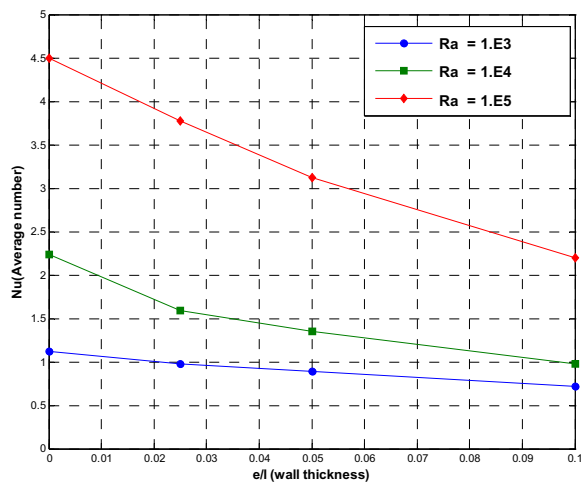

Fig. 5. Profiles of average Nusselt number for different wall thickness and for different Rayleigh number, $\mathrm{Ra}=10^{3}, 10^{4}, 10^{5}$, Pr $=0.71$.

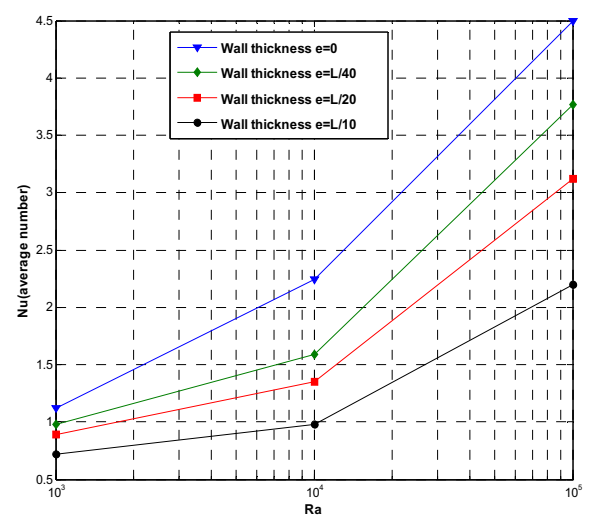

Fig. 6. Profiles of average Nusselt number for different Rayleigh number, $\mathrm{Ra}=10^{3}, 10^{4}, 10^{5}, \operatorname{Pr}=0.71$.

\section{Conclusion}

Extensive numerical results for the laminar natural convection heat transfer from a heated wall are obtained for the range of conditions as: Rayleigh number, $10^{3} \leq \mathrm{Ra}$ $\leq 10^{5}$ and Prandtl number $\operatorname{Pr}=0.71$, Concrete wall for different thicknesses is viewed with $0 \leq \mathrm{e} \leq \mathrm{L} / 10$. We are interested in convection conduction coupling. First, CFD software is used as a technique to modelling the behaviour of fluid and the thermal convection in the external wall of the house, in this context, an analogy was used for the functions which are discretized by the finite difference method and integrated in the CFD code which is based on the finite volume method. Secondly, The most important part in this work is to vary the thickness of the building material of the outer wall four times and calculate the Nusselt number and exchange coefficient of heat transfer aims to find a cloud point respectively for the thicknesses e $=0$, L / 40, L / 20 and L / 10. After, we developed a relationship that helps us to know the Nusselt number and exchange ratio for each thickness ( e ) belongs to the interval $[0, \mathrm{~L} / 10]$ by the Lagrange polynomial interpolation method, and then we developed a FORTRAN program to control the nonlinear equation of order three (equation Eq.(21).or. Eq.(22). This method for predicting exchange coefficient of convection for to optimize the design of walls in buildings. Since, Interpolation is the process of defining a function that takes on specified values at specified points.

Predictive simple correlation was developed to estimate the value of the average Nusselt number and the coefficient of heat transfer for exchange any thickness ranging from 0 to $\mathrm{L} / 10$.it just enough to replace the thickness value in equation Eq.(21), to calculate the Nusselt number planned before the design and construction of walls.

\section{Acknowledgment}

This work supported by the Research program sponsored by the Faculty of Science and Technology, Department of technology, ENERGARID laboratory, Tahri Mohamed University, Bechar, Algeria.

I would like to thank all reviewers for taking the time and energy to review our work.

\section{References}

1. Zhang, F., Cooke, P., (2012) Green Building and Energy Efficiency. Center for Advanced Studies, Cardiff University, United Kingdom.,

2. A.P. Olukoya Obafemi, Sevinç Kurtb, (2016) Environmental impacts of adobe as a building material: The north cyprus traditional building case, Case Studies in Construction Materials,4, 32-41.

3. Gunnell, K., Chrisna, D.P., Gibberd, J.,( 2009.) Green Building In South Africa: Emerging Trends. Department of Environmental Affairs and Tourism, The Republic of South Africa,

4. Ray Galvin, (2015) How many interviews are enough? Do qualitative interviews in building energy consumption research produce reliable knowledge?, Journal of Building Engineering. 1, 2 12

5. P. Davies, M. Osmani, (2011) Low carbon housing refurbishment challenges and incentives: architects' perspectives, Build. Environ. 46, 1691-1698.

6. C. Isakssona, F. Karlsson, (2006) Indoor climate in low-energy houses - an interdisciplinary investigation, Build. Environ. 41, 1678-1690.

7. R. Kyrö, J. Heinonen, S. Junnila, (2012) Housing managers key to reducing the greenhouse gas emissions of multi-family housing companies? A mixed method approach, Build. Environ. 56, 203210.

8. B. Meerbeek, M. te Kulve, T. Gritti, M. Aarts, E. van Loenen, E. Aarts, (2014) Building automation and perceived control: a field study on motorized exterior blinds in Dutch offices, Build. Environ. 79, $66-77$. 
9. Meier, C. Aragon, T. Peffer, D. Perry, M. Pritoni, (2011) Usability of residential thermostats: preliminary investigations, Build. Environ. 46 1891-1898.

10. W. Miller, L. Buys, J. Bell, (2012) Performance evaluation of eight contemporary passive solar homes in subtropical Australia, Build. Environ. 56, 57-68.

11. M. Osmani, A. O'Reilly, (2009),Feasibility of zero carbon homes in England by 2016: a house builder's perspective, Build. Environ. 44 , 1917-1924.

12. M. Pelenur, H. Cruickshank, (2013) Investigating the link between well-being and energy use; an explorative case study between passive and active domestic energy management systems, Build. Environ. 65 26-34

13. Hyo Seon Park, Changyoon Ji, Taehoon Hong, ( January 2016), Methodology for assessing human health impacts due to pollutants emitted from building materials, Building and Environment, Vol 95, PP. 133-144

14. Andrey Tsapalov, Konstantin Kovler, (January 2016), Revisiting the concept for evaluation of radon protective properties of building insulation materials, Building and environment, 95, PP 182188

15. Nadja Lynge Lyng, Lars Gunnarsen, Helle Vibeke Andersen, Vivi Kofoed-Sørensen, Per Axel Clausen, ( May 2016), Measurement of PCB emissions from building surfaces using a novel portable emission test cell, Building and Environment, 101, PP 77-84

16. Muthuvelan Thambidurai, Karthik Panchabikesan, krishna Mohan N, Velraj Ramalingam,( December 2015) Review on phase change material based free cooling of buildings-The way toward sustainability, Journal of Energy Storage, Vol 4, , PP 74-88

17. N Heinrich Badenhorst, Carl Sandrock, ( 2016) Novel method for thermal conductivity measurement through flux signal deconvolution, ournal of Energy Storage, 6,PP. 32-39

18. Najoua Bader, Abdelmottaleb Ouederni, (2016), Optimization of biomass-based carbon materials for hydrogen storage, Journal of Energy Storage, 5, PP $77-84$

19. Amr Owes Elsayed,( December 2015), Numerical study on performance enhancement of solid-solid phase change materials by using multi-nanoparticles mixtures, Journal of Energy Storage, Volume 4, PP 106-112

20. Satyender Singh, Prashant Dhiman, ( 2016), Exergoeconomic analysis of recyclic packed bed solar air heater- sustained air heating system for buildings, Journal of Energy Storage, 5, PP. 3347

21. T. Chiang, S. Natarajan, I. Walker, (2012), A laboratory test of the efficacy of energy display interface design, Energy Build. $55,471-480$.

22. M. Coleman, N. Brown, A. Wright, S. Firth, (2012), Information, communication and entertainment appliance use-insights from a UK household study, Energy Build. 54, 61-72.

23. R. Galvin, (2013), Impediments to energy-efficient ventilation of German dwellings: a case study in Aachen, Energy Build. $56,32-40$.

24. K. Gram-Hanssen, T. Christensen, P. Petersen, (2012), Air-to-air heat pumps in real-life use: are potential savings achieved or are they transformed into increased comfort? Energy Build. 53, 64-73.

25. Jovanovíc, P. Pejíc, S. Djoríc-Veljkovíc, J. Karamarkovíc, M. Djelíc, (2014), Importance of building orientation in determining daylighting quality in student dorm rooms: physical and simulated daylighting parameters' values compared to subjective survey results, Energy Build. 77,158 170.

26. J. Kanters, M. Horvat, M.-C. (2014) Dubois, Tools and methods used by architects for solar design, Energy Build. 68, 721-731.

27. M. Santamouris, S. Alevizos, L. Aslanoglou, D. Mantzios, P. Milonas, I. Sarelli, S. Karatasou, K. Cartalis, J. Paravantisca, (2014) Freezing the poor - indoor environmental quality in low and very low income households during the winter period in Athens, Energy Build. 70 ,61-70.

28. S. Karjalainen, (2011), Consumer preferences for feedback on household electricity consumption, Energy Build. 43, 458-467.

29. S. Karjalainen, (2013), Should it be automatic or manual - the occupant's perspective on the design of domestic control systems, Energy Build. 65 119126.

30. G. Menzies, J. (2005) Wherrett, Windows in the workplace: examining issues of environmental sustainability and occupant comfort in the selection of multiglazed windows, Energy Build. 37, 623630.

31. Ridley, J. Bere, A. Clark, Y. Schwartz, A. Farrd, (2014), The side by side in use monitored performance of two passive and low carbon Welsh houses, Energy Build. 82 ,13-26.

32. B. Risholt, B. Time, A. Hestnes, (2013) Sustainability assessment of nearly zero energy renovation of dwellings based on energy, economy and home quality indicators, Energy Build. 60 ,217224.

33. T. Sookchaiy, V. Monyakul, S. Thep, (2010), Assessment of the thermal environment effects on human comfort and health for the development of novel air conditioning system in tropical regions, Energy Build. $42,1692-1702$.

34. P.K. Latha , Y. Darshana , Vidhya Venugopal, (2015), Role of building material in thermal comfort in tropical climates - A review , Journal of Building Engineering, 3, 104-113.

35. K. Parsons, Human, (2003), Thermal Environment: The Effects of Hot, Cold and Moderate Environment on Human Health, Comfort and Performance, second edition,. Taylor and Francis, London. 
36. Y. Epstein, Daniel S. Moran, (2006) Thermal comfort and the heat stress indices, J. Ind. Health 44, 388-398.

37. S.A. Arngrïmsson, D.S. Petitt, M.G. Stueck, D.K. Jorgensen, K.J. Cureton, (2004), Cooling vest worn during active warm-up improves $5-\mathrm{km}$ run performance in the heat, J. Appl. Physiol. 96 18671874.

38. González, G. Craig, M.J. John, (2008), The cardiovascular challenge of exercising in the heat, J. Physiol. 586 45-53.

39. Wesseling, J. Crowe, C. Hogstedt, K. Jakobsson, R.A. Lucas, D.H. Wegman, (2014), Resolving the enigma of the Mesoamerican nephropathy-men - a research workshop summary, Am. J. Kidney Dis. 63 (3) ,396-404.

40. R.S. Bridger, (2003), Introduction to Ergonomics, second ed., Taylor and Francis, London, p. 780.

41. G.P. Bates, J. Schneider, (2008), Hydration status and physiological workload of UAE construction workers - a prospective longitudinal observational study, J. Occup. Med. Toxicol. 3 21-26.

42. P. Dutta, V. Chorsiya, (2013) Scenario of climate change and human health in India, Int. J. Innov. Res. Dev. 2 (8) ,157-160.

43. Benachour E. and al,(2015)., Study of the Influence of the Mural Heating on the Convection in the Building in Arid Area, international review of mechanical engineering (IREME), vol.9N.1,

44. S. V. Patankar, ( 1980)., Numerical Heat Transfer and Fluid Flow, McGraw-Hill New York,

45. De Vahl Davis G, (1983), Natural convection of air in a square cavity. A bench mark numerical solution. 